\title{
INISIASI MENYUSU DINI MEMPENGARUHI PERDARAHAN KALA IV PADA PRIMIPARA DI PUSKESMAS TANAH KALI KEDINDING SURABAYA
}

\author{
Yeni Tri Puji Lestari", R. Khairiyatul Afiyah** \\ (UNUSA, FIK, Prodi SI Keperawatan - Jl. Smea 57 Surabaya) \\ E-mail: Satu_37@yahoo.co.id
}

\begin{abstract}
Early initiation of breastfeeding is one of the ways to decrease the incidence rate of bleeding in the fourth stage. The incidence of bleeding in the fourth stage still occurs in Puskesmas Tanah Kalikedinding (Community Health Center). The pre-study done in JanuaryMarch 2013 showed that among 52 primiparous labors showed that 18 people have done early initiation of breastfeeding, whereas 7 people had bleeding in the fourth stage. Therefore, this study was purposed to find out the correlation between the early initiation of breastfeeding and the bleeding in the fourth stage in the primiparous mothers hospitalized in Puskesmas Tanah Kalikedinding Surabaya. The design of study was analytic-cross sectional. The population involved all primiparous mothers, totally 17 people chosen as the samples by using probability sampling in which the total sampling technique was applied in this study. The instruments used in this study were check list and observation. The data were processed by using Mann-Whitney's test and SPSS with the significance level of $\alpha(0.05)$. If $\mathrm{p}<\alpha$, it showed that $\mathrm{H}_{0}$ was rejected illustrating that there was a correlation between the early and the bleeding in the fourth stage. The result of study showed that most of the respondents $(64.7 \%)$ did early initiation of breastfeeding, whereas most of them $(70.6 \%)$ did not have any bleeding. The result of Mann-Whitney's test showed that $p=0.016$ which meant that there was a correlation between the early initiation of breastfeeding and the bleeding in the fourth stage in primiparous mothers hospitalized in Puskesmas TKK Surabaya. In conclusion, the early initiation of breastfeeding can prevent the bleeding in the fourth stage. Thus, the midwives are expected to increase the midwifery care in efforts to decrease the incidence rate of bleeding in the fourth stage by applying the early initiation of breastfeeding when accompanying labor.
\end{abstract}

Abstrak : Inisiasi Menyusu Dini merupakan salah satu cara untuk mengurangi kejadian perdarahan kala IV. Masih adanya kejadian perdarahan kala IV di Puskesmas Tanah Kalikedinding. Data awal yang didapat bulan Januari-Maret 2013 dari 52 persalinan primipara 18 orang dilakukan IMD dan 7 orang mengalami perdarahan kala IV.Tujuan penelitian mengetahui hubungan IMD dengan perdarahan kala IV pada primipara di Puskesmas Tanah Kalikedinding Surabaya. Desain penelitian analitik dengan pendekatan cross sectional. Populasi semua ibu bersalin primipara sebanyak 17 responden. Sampel sebanyak 17 responden dengan probability sampling teknik total sampling. Instrumen penelitian lembar checklist dan observasi. Data diolah dengan bantun SPSS menggunakan uji Mann-whitney dengan tingkat signifikan $(\alpha=0,05)$, apabila $\rho$ $<\alpha$ maka $\mathrm{H}_{0}$ ditolak ada hubungan antara IMD dengan perdarahan kala IV. Hasil penelitian sebagian besar $(64,7 \%)$ responden melakukan IMD, sebagian besar $(70,6 \%)$ responden tidak mengalami perdarahan. Hasil uji Mann-whitney didapatkan tingkat signifikansi $\rho=0,016$. Artinya ada hubungan antara Inisiasi Menyusu Dini dengan perdarahan kala IV pada primipara di Puskesmas Tanah Kalikedinding Surabaya. IMD dapat mencegah terjadinya perdarahan kala IV, diharapkan bidan dapat meningkatkan asuhan kebidanan dalam upaya mengurangi kejadian perdarahan kala IV dengan cara menerapkan Inisiasi Menyusu Dini pada pertolongan persalinan.

Kata kunci : inisiasi menyusu dini, perdarahan 


\section{PENDAHULUAN}

Terdapat beberapa cara untuk mencegah terjadinya perdarahan kala IV, salah satunya adalah dengan Inisiasi Menyusu Dini yang dapat meningkatkan kontraksi otot rahim dan menghentikan perdarahan. Inisiasi Menyusu Dini (IMD) merupakan proses satu jam pertama pasca bayi lahir, melatih bayi untuk secara naluriah menemukan sendiri puting susu ibunya. Saat bayi menghisap puting susu ibu, merangsang kontraksi otot rahim sehingga perdarahaan sesudah melahirkan dapat lebih cepat berhenti dan rahim akan lebih cepat kembali seperti semula (Roesli, 2008). Kenyataan di lapangan cakupan Inisiasi Menyusu Dini masih sangat rendah dan masih adanya kejadian perdarahan kala IV yang mengancam setiap nyawa ibu bersalin.

Menurut Utami Roesli (2008), di Indonesia hanya $4 \%$ persalinan yang telah menerapkan program Inisiasi Menyusu Dini, sedangkan di Jawa Timur program Inisiasi Menyusu Dini telah diterapkan 17\%, dan 83\% persalinan tidak menerapkan IMD. Di Puskesmas Tanah Kalikedinding Surabaya pada bulan Januari-Maret 2013 di dapatkan dari 52 persalinan primipara 18 orang $(35 \%)$ dilakukan Inisiasi Menyusu Dini dan 7 orang $(13 \%)$ mengalami perdarahan kala IV. Petugas kesehatan telah membantu dalam penerapan Inisiasi Menyusu Dini di Puskesmas Tanah Kalikedinding Surabaya tetapi masih banyak ibu primipara yang tidak melakukan Inisiasi Menyusu Dini.

Inisiasi Menyusu Dini merupakan kegiatan yang sangat penting untuk di lakukan karena memberikan banyak manfaat bagi ibu dan bayi. Manfaat bagi bayi adalah mempertahankan suhu badan bayi tetap hangat, memperoleh kolostrum yang sangat bermanfaat bagi sistem kekebalan bayi, melatih reflek menghisap bayi. Sedangakan manfaat bagi ibu adalah meningkatkan hubungan khusus antara ibu dan bayi, mengurangi stress ibu setelah melahirkan, memperlancar produksi ASI dan merangsang kontraksi otot rahim sehingga mengurangi resiko perdarahan. Melalui sentuhan, hisapan dan jilatan bayi pada puting susu ibu akan merangsang pengeluaran hormon oksitosin yang penting. Oksitosin akan menyebabkan uterus berkontraksi sehingga membantu pengeluaran plasenta dan mengurangi terjadinya perdarahan post partum. Selain itu gerakan kaki bayi pada saat merangkak di perut ibu akan membantu massage uterus untuk merangsang kontraksi uterus (Roesli, 2008). Karena itu Inisiasi Menyusu Dini dianjurkan di lakukan oleh semua ibu bersalin, apabila tidak di lakukan bayi dapat mengalami kedinginan, ikatan batin ibu dan bayi tidak terbentuk dan perdarahan kala IV tidak dapat dicegah (Shinta, 2008).

Salah satu metode yang digalakkan pemerintah untuk mengurangi kejadian perdarahan pada ibu bersalin adalah dengan tehnik IMD. Dengan cara menyosialisasikan rumah sakit sayang bayi, melatih tenaga kesehatan terkait yang dapat membantu ibu untuk melakukan Inisiasi Menyusui Dini yang benar, tenaga kesehatan memberikan informasi tentang Inisiasi Menyusui Dini dan melatih orang tua cara menyusui yang benar minimal dua kali selama antenatal.

Berdasarkan fenomena diatas, penulis tertarik untuk melakukan penelitian tentang Hubungan Inisiasi Menyusu Dini dengan perdarahan Kala IV pada Primipara di Puskesmas Tanah Kalikedinding Surabaya.

\section{METODE PENELITIAN}

Dalam penelitian ini jenis yang digunakan adalah analitik dengan desain cross sectional, Populasi dan sampel dalam penelitian ini semua semua ibu bersalin primipara di Puskesmas Tanah Kalikedinding pada bulan Juni 2013 sebanyak 17 orang.

Pengambilan sampel dilakukan secara probability sampling. Instrumen penelitian menggunakan lembar observasi dan checklist.

\section{HASIL PENELITIAN}

1. Pelaksanaan Inisiasi Menyusu Dini 
Pelaksanaan Inisiasi Menyusu Dini disajikan pada tabel 5.4

Tabel 5.4 Distribusi frekuensi Pelaksanaan Inisiasi Menyusu Dini pada ibu bersalin primipara di Puskesmas Tanah Kalikedinding Surabaya bulan Juni Tahun 2013.

\begin{tabular}{llcc}
\hline No & $\begin{array}{l}\text { Inisiasi } \\
\text { Menyusu }\end{array}$ & Frekuensi & $\begin{array}{c}\text { Persentase } \\
(\%)\end{array}$ \\
& Dini & & \\
\hline 1. & Dilakukan & 11 & 64,7 \\
2. & $\begin{array}{l}\text { Tidak } \\
\text { dilakukan }\end{array}$ & 6 & 35,3 \\
\hline & Jumlah & 17 & 100 \\
\hline
\end{tabular}

Sumber : Data Primer Hasil Data checklist, Juni 2013

Dari tabel 5.4 menunjukkan dari 17 responden sebagian besar $(64,7 \%)$ ibu bersalin primipara melakukan Inisiasi Menyusu Dini.

2. Distribusi kejadian perdarahan kala $1 \mathrm{~V}$ ibu bersalin

Kejadian perdarahan kala 1V ibu bersalindisajikan pada table 5.5

Tabel 5.5 Distribusi frekuensi kejadian perdarahan kala $1 \mathrm{~V}$ pada ibu bersalin primipara di Puskesmas Tanah Kalikedinding Surabaya bulan Juni Tahun 2013.

\begin{tabular}{clcc}
\hline No & $\begin{array}{l}\text { Kejadian } \\
\text { Perdarahan }\end{array}$ & Frekuensi & $\begin{array}{c}\text { Persentase } \\
(\%)\end{array}$ \\
\hline 1. & Tidak & 12 & 70,6 \\
2. & $\begin{array}{l}\text { Perdarahan } \\
\text { Perdarahan }\end{array}$ & 5 & 29,4 \\
\hline & Jumlah & 17 & 100 \\
\hline
\end{tabular}

Sumber : Data Primer Hasil Data Observasi, juni 2013

Dari tabel 5.5 menunjukkan dari 17 responden sebagian besar $(70,6 \%)$ ibu bersalin primipara tidak mengalami perdarahan kala IV.

3. Hubungan Inisiasi Menyusu Dini dengan perdarahan kala IV pada primipara di di Puskesmas Tanah Kalikedinding Surabaya.

Hubungan Inisiasi Menyusu Dini dengan perdarahan kala IV pada primipara yang diteliti dapat disajikan dalam bentuk tabulasi silang sebagai berikut:

Tabel 5.6 Tabulasi silang hubungan Inisiasi Menyusu Dini dengan perdarahan kala IV pada primipara di Puskesmas Tanah Kalikedinding Surabaya.

\begin{tabular}{|c|c|c|c|c|c|}
\hline \multirow[t]{5}{*}{ No } & \multirow{4}{*}{$\begin{array}{l}\text { Inisiasi } \\
\text { Menyusu } \\
\text { Dini }\end{array}$} & Perdarahan & & \multirow{3}{*}{\multicolumn{2}{|c|}{ Jumlah }} \\
\hline & & Tidak Perda & \multirow[b]{2}{*}{$\begin{array}{l}\text { Perdaraha } \\
\mathrm{n}\end{array}$} & & \\
\hline & & & & & \\
\hline & & \multirow[t]{2}{*}{ n $\%$} & & & $\%$ \\
\hline & & & n $\%$ & \multirow[b]{2}{*}{11} & \\
\hline 1. & Dilakukan & $10(90,9)$ & $1(9,1)$ & & 100 \\
\hline 2. & Tdk & $2(33,3)$ & & 6 & 100 \\
\hline & dilakukan & \multicolumn{2}{|r|}{$4(66,7)$} & & \\
\hline \multirow{2}{*}{\multicolumn{2}{|c|}{ Jumlah }} & $12(70,6)$ & & 17 & 100 \\
\hline & & \multicolumn{2}{|r|}{$5(29,4)$} & & \\
\hline
\end{tabular}

Sumber : Data Primer Hasil Data Checklist dan Observasi, Juni 2013

Dari hasil tabulasi di atas, diperoleh dari 11 responden yang melakukan Inisiasi Menyusu Dini hampir seluruh responden $(90,9 \%)$ tidak mengalami perdarahan, sedangkan sebagian kecil $(9,1 \%)$ mengalami perdarahan. Dari 6 responden yang tidak melakukan Inisiasi Menyusu Dini didapatkan hampir setengahnya $(33,3 \%)$ tidak mengalami perdarahan, sebagian besar $(66,7 \%)$ terjadi perdarahan.

Hasil analisis data dengan menggunakan uji Mann - Whitney dengan derajat kemaknaan $\alpha$ $=0,05$ didapatkan $\rho=0,016$ sehingga $\rho<\alpha$ maka $\mathrm{H}_{0}$ ditolak, dengan demikan disimpulkan bahwa ada hubungan antara Inisiasi Menyusu Dini dengan perdarahan kala IV pada primipara di Puskesmas Tanah Kalikedinding Surabaya.

\section{PEMBAHASAN}

Dalam proses IMD bayi secara naluriah berusaha menemukan puting susu dan segera menghisapnya. Hal ini sesuai dengan pendapat Utami Roesli (2008) bahwa secara refleks bayi akan bergerak ke arah payudara. Areola sebagai sasaran, dengan kaki menekan perut ibu, ia menjilat-jilat kulit ibu, menghentakhentakan kepala ke dada ibu, menoleh ke 
kanan dan ke kiri serta menyentuh dan meremas daerah puting susu dan sekitarnya dengan tangannya yang mungil.

Dari sebagian besar $11(64,7 \%)$ ibu bersalin yang berhasil melakukan Inisiasi Menyusu Dini (IMD), didapatkan sembilan ibu bersalin berhasil melakukan IMD sesuai prosedur dengan langkah segerah setelah bayi lahir, bayi dikeringkan, dipotong tali pusatnya dan diikat, kemudian bayi dietakkan di dada ibu untuk mencari, menemukan, dan menghisap puting susu ibu, rata-rata membutuhkan waktu \pm 40 menit. Dan dua ibu bersalin berhasil melakukan IMD namun tidak sesuai prosedur disebabkan adanya lilitan tali pusat pada bayi responden. Pada bayi yang mengalami lilitan tali pusat, begitu bayi lahir tidak segera diletakkan di atas perut ibu, melainkan di depan vulva sambil dikeringkan sampai pemotongan tali pusat selesai. Setelah tali pusat dipotong bayi baru diletakkan di atas perut ibu untuk memulai proses inisiasi menyusu dini dengan waktu \pm 70 menit.

Inisiasi Menyusu Dini dikatakan berhasil apabila segera setelah bayi lahir, setelah tali pusat dipotong, bayi tengkurapkan didada ibu dengan kulit bayi melekat pada kulit ibu, biarkan kontak kulit bayi kekulit ibu menetap selama setidaknya 1 jam bahkan lebih sampai bayi dapat menemukan puting dan menyusu sendiri (JNPK-KR,2007). Jika bayi belum berhasil melakukan Inisiasi Menyusu Dini dalam waktu 1 jam, posisikan bayi lebih dekat dengan puting ibu dan biarkan kontak kulit dengan kulit selama 30- 60 menit berikutnya. Jika bayi masih belum berhasil melakukan Inisiasi Menyusu Dini dalam waktu 2 jam, pindahkan ibu ke ruang nifas dengan bayi tetap di dada ibu. Lanjutkan asuhan BBL dan kemudian kembalikan bayi ke ibu untuk menyusu (APN, 2008).

Hampir setengahnya $6(35,3 \%)$ ibu bersalin yang tidak dilakukan IMD segera setelah bayi lahir, didapatkan sebanyak dua responden tidak murni melakukan IMD karena bayi tidak bisa menemukan puting susu ibunya dalam waktu lebih dari 1 jam meskipun langkah-langkah IMD sudah dilakukan dengan benar sehingga bayi dibantu oleh petugas untuk menemukan puting susu ibunya. Hal tersebut terjadi pada bayi dengan proses persalinan yang lebih lama dari bayi-bayi yang lain, kemungkinan pada saat itu bayi mengalami tekanan pada kranial sehingga mengganggu kemampuan alami bayi untuk menemukan puting sendiri. Sedangkan dua responden tidak murni melakukan IMD karena banyaknya pasien dan terbatasnya tenaga petugas kesehatan sehingga bayi dibantu petugas dalam menemukan puting susu ibu. Dan dua responden tidak dilakukan IMD karena ibu responden mengalami perdarahan sehingga petugas mengutamakan menghentikan perdarahan daripada melakukan IMD.

Menurut Reeder, Martin \& Griffin (2011), Perdarahan pascapartum langsung terjadi selama 24 jam pertama setelah pelahiran. Kondisi ini paling sering disebabkan oleh atonia uterus akibat distensi uterus yang berlebihan selama kehamilan atau factor-faktor yang menyebabkan komplikasi persalinan dan pelahiran. Berdasarkan hasil penelitian sebagian besar $12(70,6 \%)$ ibu bersalin tidak mengalami perdarahan dengan ciri rata-rata jumlah darah 200cc, tensi darah 120/80 mmHg, suhu $37{ }^{\circ} \mathrm{C}$, TFU dua jari bawah pusat, kontraksi uterus keras, kandung kemih kosong, responden yang jumlah perdarahannya kurang dari $500 \mathrm{cc}$ adalah responden berusia antara 20-35 tahun karena pada usia 20-35 tahun merupakan usia reproduktif dimana alat-alat reproduksi sudah berkembang dengan sempurna sehingga proses persalinan dapat berlangsung dengan normal dan perdarahan pascapartum dapat dicegah . Hampir setengahnya $5 \quad(29,4 \%) \quad$ ibu bersalin mengalami perdarahan dengan ciri rata-rata jumlah darah $600 \mathrm{cc}$, tensi darah 110/80 $\mathrm{mmHg}$, suhu $37^{\circ} \mathrm{C}$, TFU satu jari bawah pusat, kontraksi uterus lembek, kandung kemih kosong, responden yang jumlah perdarahannya lebih dari $500 \mathrm{cc}$ berumur di bawah 20 tahun karena pada usia di bawah 20 tahun fungsi reproduksi seorang wanita belum berkembang dengan sempurna. 
Menurut Arif Mansjoer (1999), perdarahan dipengaruhi beberapa faktor yaitu usia, gravida, paritas, kadar hemoglobin, serta antenatal care. Pada usia 20-35 tahun merupakan usia reproduktif dimana alat-alat reproduksi sudah berkembang dengan sempurna. Sedangkan wanita yang melahirkan anak pada usia dibawah 20 tahun atau lebih dari 35 tahun merupakan faktor risiko terjadinya perdarahan pascapersalinan. Hal ini dikarenakan pada usia di bawah 20 tahun fungsi reproduksi seorang wanita belum berkembang dengan sempurna, sedangkan pada usia diatas 35 tahun fungsi reproduksi seorang wanita sudah mengalami penurunan dibandingkan fungsi reproduksi normal sehingga kemungkinan untuk terjadinya komplikasi pascapersalinan terutama perdarahan akan lebih besar.

Menurut Utami Roesli (2008) pada saat bayi menghentakkan kepala ke dada ibu, sentuhan tangan bayi ke puting susu ibu dan sekitarnya, jilatan dan hisapan bayi pada puting susu ibu akan merangsang pengeluaran hormon oksitosin. Pelepasan hormon oksitosin ini membantu proses involusi uterus dan membantu mengendalikan perdarahan.

Manfaat Inisiasi Menyusu Dini, selain membantu mengendalikan perdarahan, juga membantu meningkatkan hubungan khusus ibu dan bayi, merangsang pengeluaran hormon prolaktin sehingga meningkatkan produksi ASI, mengurangi stres ibu setelah melahirkan serta memberikan efek relaksasi pada ibu setelah bayi selesai menyusu. Bagi bayi manfaatnya antara lain, mempertahankan suhu bayi tetap hangat, memberikan kekebalan pasif pada ibu, meningkatkan kecerdasan, membantu bayi mengkoordinasikan kemampuan hisap, telan, nafas, serta melatih motorik saat menyusu, sehingga mengurangi kesulitan menyusu (Utami Roesli, 2008).

\section{SIMPULAN}

Berdasarkan hasil penelitian yang telah diuraikan, maka dapat dirumuskan simpulan sebagai berikut:
1. Ibu bersalin primipara di Puskesmas Tanah Kalikedinding Surabaya sebagian besar melakukan Inisiasi Menyusu Dini.

2. Ibu bersalin primipara di Puskesmas Tanah Kalikedinding Surabaya sebagian besar tidak mengalami perdarahan kala IV.

3. Ada hubungan Inisiasi Menyusu Dini dengan perdarahan kala IV pada primipara di Puskesmas Tanah Kalikedinding Surabaya

\section{DAFTAR RUJUKAN}

Arikunto, S. (2006). Prosedur Penelitian Suatu Pendekatan Praktek. Jakarta. Rineka Cipta.

Bobak, Lowdermilk Jensen. (2004). Buku Ajar Keperawatan Maternitas. Jakarta. EGC

Darma, Kelana Kusuma. (2011). Metodologi Penelitian Keperawatan. Jakarta. Trans Info Media

Depkes RI. (1999). Faktor-faktor inisiasi menyusu dini. Retrieved at March, 2009. From www.google.com

Jaringan Nasional Pelatih Klinik Kesehatan Reproduksi. (2008). Asuhan Persalinan Normal. Jakarta. Departemen Kesehatan Republik Indonesia

Mansjoer, Arif. dkk. ed.(1999). Kapita Selekta Kedokteran. Jakarta. Media Ausculapius

Manuaba, Ida Bagus Gde. (2001). Kapita Selekta Penatalaksanaan Rutin Obstetri, Ginekologi dan KB. Jakarta . EGC.

Manuaba, Ida Bagus Gde.(1998). Ilmu kebidanan, Penyakit Kandungan dan Keluarga Berencana untuk Pendidikan Bidan. Jakarta, EGC

McLEOD, John. (2008). Pengantar Konseling Teori dan Studi Kasus. Jakarta, Kencana

Mochtar, Rostam. (1998). Sinopsis Obstetri. Jakarta, EGC

Notoatmodjo, Sukidjo. (2005). Metedologi penelitian kesehatan. Jakarta. Rineka Cipta.

Nursalam. (2001). Konsep Dan Penerapan Metodologi Penelitian Ilmu 
Keperawatan. Jakarta. Salemba Medika

Prawirohardjo, Sarwono. (2005). Ilmu Kebidanan. Jakarta. Yayasan Bina Pustaka Sarwono Prawirohardjo

Purnomo, Windhu. (2012). Pengantar Biostatistika. Unair

Rahardian, Paramita P. (2007). Manfaat Inisiasi Menyusu Dini. Retrieved at March, 2009. form www.google.com

Resty K. (2000). Angka Kematian Maternal di Indonesia. Retrieved at March, 2009. From www.google.com

Roesli,Utami. (2008). Inisiasi Menyusu Dini. Jakarta. PT Gramedia Pustaka Utama

Rosita. (2007). Manfaat Inisiasi Menyusu Dini. Diakses Mei, 2013.

Safe Motherhood. (2001). Modul Hemoragi Post Partum. Jakarta. EGC.

Saifuddin, Abdul, Bahri. (2000). Buku Panduan Praktis Pelayanan Kesehatan Maternal dan Neonatal. Jakarta. Yayasan Bina Pustaka Sarwono Prawirohardjo.

Shinta. (2008). Inisiasi Menyusu Dini. Diakses Mei, 2013. Www.Ayah Bunda.htm

Siregar, Arifin. (2004). Inisiasi Menyusu Dini. Diakses Mei, 2013. www.Ibu dan anak.htm

Sofian . (2012). Persalinan. Diakses Mei, 2013. ttp://www.scribd.com/doc /8649214/ PERSALINAN

Varney, Helen. (2006). Buku Ajar Asuhan Kebidanan. Jakarta, EGC 